\title{
Comparison of Symbiodiniaceae diversities in different members of a Palythoa species complex (Cnidaria: Anthozoa: Zoantharia) - implications for ecological adaptations to different microhabitats
}

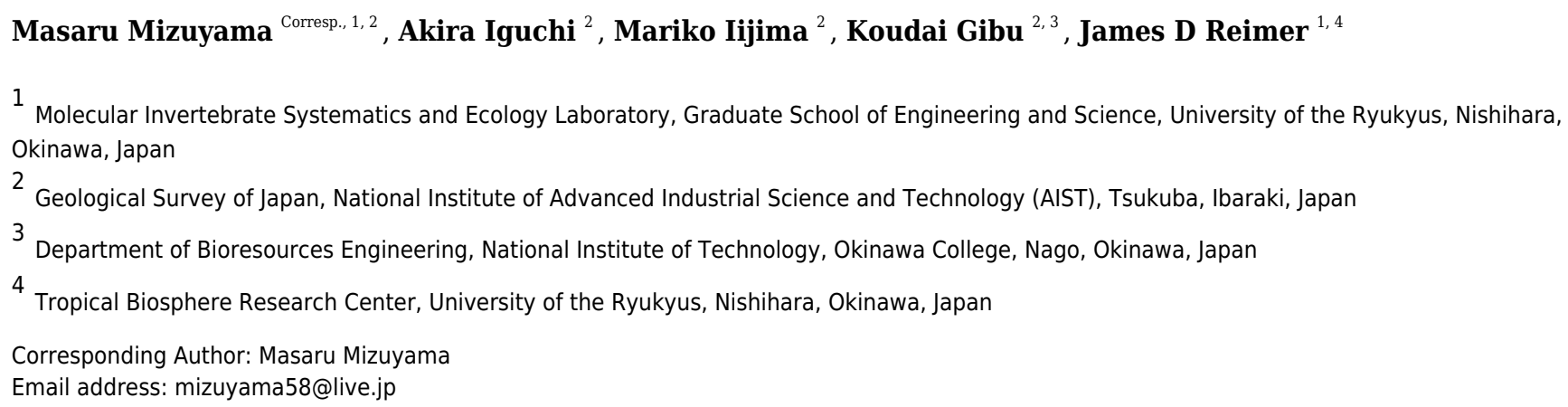

In this study we compared genotypes of zoantharian host-associating algal symbionts among Palythoa species, which are among the dominant benthic reef organisms in the Ryukyu Archipelago, Japan, and evaluated Symbiodiniaceae diversities of closely related congeneric Palythoa species. We targeted a species complex of the zoantharian genus Palythoa ( $P$. tuberculosa, $P$. sp. yoron, $P$. mutuki) living among different microhabitats in a narrow reef area of Tokunoshima Island. For phylogenetic analyses, we used two DNA marker regions; nuclear internal transcribed spacer (ITS) and plastid mini-circle non-coding region ( $p_{s b A^{n c r}}$ ), both of which have previously been used to determine Symbiodiniaceae genotypes of zoantharian species. Our results showed that all Palythoa species hosted symbionts of the genus Cladocopium, with genotypic compositions of this genus showing some variations among the three different Palythoa species. Additionally, we found that the Cladocopium genotypic composition was statistically different among Palythoa species, and among $P$. tuberculosa specimens in different microhabitats. Our results suggest that ecological divergence among these three Palythoa species may be related to differing Symbiodiniaceae diversities that may in turn contribute to eco-physiological adaptation into different microhabitats on coral reefs. 
1 Title:

2 Comparison of Symbiodiniaceae diversities in different members of a Palythoa species complex

3 (Cnidaria: Anthozoa: Zoantharia) - implications for ecological adaptations to different 4 microhabitats

5

6 Authors and their affiliations:

7 Masaru Mizuyama ${ }^{1,2}$, Akira Iguchi², Mariko Iijima², Kodai Gibu ${ }^{2,3}$, James D Reimer ${ }^{1,4}$

$9{ }^{1}$ Molecular Invertebrate Systematics and Ecology Laboratory, Graduate School of Engineering and Science, 10 University of the Ryukyus, Senbaru 1, Nishihara, Okinawa, Japan

$11{ }^{2}$ Geological Survey of Japan, National Institute of Advanced Industrial Science and Technology (AIST), 12 Higashi 1-1-1, Tsukuba, Ibaraki, Japan

$13{ }^{3}$ Department of Bioresources Engineering, National Institute of Technology, Okinawa College, Henoko 14 905, Nago, Okinawa, Japan

$15{ }^{4}$ Tropical Biosphere Research Center, University of the Ryukyus, Senbaru 1, Nishihara, Okinawa, Japan 16

17 Corresponding Author:

18 Masaru Mizuyama ${ }^{1}$

19 Email address: mizuyama58@1ive.jp 
20 Abstract

21 In this study we compared genotypes of zoantharian host-associating algal symbionts among Palythoa 22 species, which are among the dominant benthic reef organisms in the Ryukyu Archipelago, Japan, and 23 evaluated Symbiodiniaceae diversities of closely related congeneric Palythoa species. We targeted a species 24 complex of the zoantharian genus Palythoa (P. tuberculosa, P. sp. yoron, P. mutuki) living among different microhabitats in a narrow reef area of Tokunoshima Island. For phylogenetic analyses, we used two DNA marker regions; nuclear internal transcribed spacer (ITS) and plastid mini-circle non-coding region $\left(\mathrm{psbA}^{\mathrm{ncr}}\right)$, both of which have previously been used to determine Symbiodiniaceae genotypes of zoantharian species. Our results showed that all Palythoa species hosted symbionts of the genus Cladocopium, with genotypic compositions of this genus showing some variations among the three different Palythoa species. Additionally, we found that the Cladocopium genotypic composition was statistically different among Palythoa species, and among P. tuberculosa specimens in different microhabitats. Our results suggest that ecological divergence among these three Palythoa species may be related to differing Symbiodiniaceae diversities that may in turn contribute to eco-physiological adaptation into different microhabitats on coral reefs.

Keywords: Zoantharia, Palythoa species complex, Symbiodiniaceae, ecological divergence

\section{Introduction}

Zoantharians (Anthozoa: Zoantharia) belong to the phylum Cnidaria and can be dominant organisms in shallow coral reef areas (e.g., Burnett et al., 1994). In particular, the genus Palythoa is often among the most dominant benthos in coral reef areas (Irei, Nozawa \& Reimer, 2011; Santos et al., 2016; Reimer et al., 42 2017a).

43 We recently reported on four putative Palythoa species (P. tuberculosa, $P$. sp. yoron, $P$. mutuki, and $P$. aff. mutuki) that form a species complex, and were observed to all occur within a narrow range of coral reefs in southern Japan (Mizuyama, Masucci \& Reimer, 2018). For example, P. tuberculosa tends to occur across a wide range of habitats from shallow to deeper areas, from the intertidal zone to the mesophotic reef slope (Mizuyama, Masucci \& Reimer, 2018), and has been reported from tropical to temperate regions (Reimer, Takishita \& Maruyama, 2006). On the other hand, the other three Palythoa species appear to more restricted compared to P. tuberculosa in terms of their distribution and habitats within coral reefs. Palythoa mutuki is the second most dominant species in this genus in Okinawa and is often dominant at the reef edge, in 
52 yet to be formally described, but tends to occur on reef flats and backreef moats where it is exposed to 53 strong water currents (Shiroma \& Reimer, 2010). Although there is little published information on $P$. aff. 54 mutuki, it has been observed near P. mutuki colonies on the reef flat (Mizuyama, Masucci \& Reimer, 2018). 55 Although molecular delineation of these Palythoa species groups was unsuccessful with molecular data, 56 likely due to incomplete lineage sorting, they can be distinguished via morphological and reproductive data (Mizuyama, Masucci \& Reimer, 2018). In addition, these Palythoa species display different microhabitat patterns within the coral reef, but it is still unclear how these species would have diversified under almost completely sympatric conditions.

Symbiodiniaceae endosymbiotic dinoflagellates are symbiotic with various metazoan phyla including Cnidaria (LaJeunesse et al., 2018). Many zoantharians maintain Symbiodiniaceae, similar to reef-building corals (Noda et al., 2017; Wee, Kurihara \& Reimer, 2019). In the case of scleractinian corals, symbiotic relationships with Symbiodiniaceae are important for host survival in various environments (Baker, 2003), and can contribute to ecological divergence of coral host species (Winters et al., 2009). Previous molecular studies have reported that species composition of Symbiodiniaceae is closely related to host genotypes in corals (e.g. Bongaerts et al., 2010; Pinzon \& LaJeunesse, 2011). Thus, information on the composition Symbiodiniaceae of the four Palythoa species above would also be helpful to understand their ecological divergence into different microenvironments within a reef. In particular, genotypic composition of symbiotic algae would be informative for understanding ecological divergence of these species because the genetic and/or community changes of microbiomes are expected to be faster than that of the hosts themselves (Torda et al., 2017), facilitating eco-physiological adaptation of holobionts into different microenvironments (e.g., Reimer et al., 2017b; Wee, Kurihara \& Reimer, 2019). In this study, we aimed to 1) compare diversities of symbionts among the closely related Palythoa species $P$. tuberculosa, $P$. sp. yoron, $P$. mutuki and $P$. aff. mutuki, and 2) determine if diversities of symbionts explain eco-physiological adaptations to microhabitats of each species that entailed divergences among them ( $P$. tuberculosa, $P$. sp. yoron and $P$. mutuki).

\section{Materials \& Methods}

Specimens collection

81 Eighty-two colonies of three Palythoa species (P. tuberculosa, P. sp. yoron, and P. mutuki) were collected 
$8427.76998333 \mathrm{~N}, 129.03988611$ E) for P. tuberculosa (Fig. 2C); reef flat 1 (Fig. 2D, $27.76997777 \mathrm{~N}$, 85129.03925000 E) for P. tuberculosa (Fig. 2E) and P. mutuki; reef flat 2 (Fig. 2F, 27.77195277 N, 86129.03843611 E) for P. mutuki (Fig. 2G); and backreef moat (Fig. 2H, 27.76990833 N, 129.03855833 E) 87 for P. tuberculosa and P. sp. yoron (Fig. 2I). To avoid collecting clones, we collected individuals from 88 clearly different colonies while maintaining a set distance from each other of at least $1 \mathrm{~m}$. In a previous study, even when closer to each other (within approximately $50 \times 50 \mathrm{~cm}$ ), no clones were observed in Zoanthus (Cnidaria: Anthozoa: Zoantharia) colonies (Albinsky et al., 2018). In addition, eighteen previously collected specimens of Palythoa species including 10 P. aff. mutuki specimens from Mizuyama, Masucci \& Reimer (2018) were also examined in this study (Table 1).

\section{DNA extraction and PCR amplification}

95 From each of these specimens, several polyps were cut with a surgical knife and DNA was extracted using 96 DNeasy Blood and Tissue Kit (QIAGEN). DNA concentrations were checked by Qubit Fluorometer 97 (ThermoFisher, Waltham, USA). Two molecular markers for genotyping symbiotic algae of Palythoa 98 species were examined: nuclear internal transcribed spacer ribosomal DNA (ITS-rDNA) region including partial 18S-ITS1-5.8S-ITS2-partial 28S (primers zITSf: CCG GTG AAT TAT TCG GAC TGA CGC AGT and ITS4: TCC TCC GCT TAT TGA TAT GC, Baillie, Belda-Baillie \& Maruyama, 2000; appx. 700$750 \mathrm{bp}$ ) and plastid mini-circle non-coding region DNA (psbA ${ }^{\text {ncr }}$ ) (primers 7.4-Forw: GCA TGA AAG AAA TGC ACA CAA CTT CCC and 7.8-Rev: GGT TCT CTT ATT CCA TCA ATA TCT ACT G, Moore et al., 2003; appx. 800-850 bp). These regions were amplified according to the PCR thermal conditions in

104 Wee, Kurihara \& Reimer. (2019). Amplified PCR products of symbionts were directly sequenced, and sequence data were manually checked based on the chromatogram files and low quality sites were removed at the 5' and 3' ends by BioEdit v.7.0.5.3 (Hall, 1999). Obtained sequences were deposited in the GenBank database (MN654128-MN654306, Table 1).

\section{Haplotype network inference and phylogenetic estimation}

110 Obtained sequences for ITS-rDNA, $\mathrm{psbA}^{\mathrm{ncr}}$ forward and reverse regions were aligned, respectively. In order

111 to discriminate taxa of Symbiodiniaceae, we extracted the ITS2 region utilizing SymPortal (Hume et al., 112 2019; https://symportal.org/) and performed BLASTN search against the nt database using the NCBI 113 website (https://blast.ncbi.nlm.nih.gov/Blast.cgi) for ITS-rDNA sequences. Haplotype network inference 114 was performed for ITS-rDNA sequences using the alignment with TCS networks method (Clement et al., 115 2002) in PopART (Leigh \& Bryant, 2015). Any columns in the alignment with gaps or ambiguous sites 
116 were automatically masked in the inference. The phylogenetic analyses were performed by MEGA version

117 X (Kumar et al., 2018) and any loci with ambiguous (double peaks) sites and gaps was automatically deleted

118 completely for calculation in order to avoid over/underestimation of genetic distance among each sequence.

119 Molecular phylogenetic trees of each marker were constructed by maximum likelihood (ML) and neighbor

120 joining (NJ) methods under the $\mathrm{JC}+\mathrm{G}$ model for ITS-rDNA region and the JC model for $\mathrm{psbA}^{\text {ncr }}$ regions

121 adopted by modeltest program within MEGA X. The significance of each node was tested by bootstrap test

122 with 1,000 replications. Bayesian inference was performed using BEAST2 (Bouckaert et. al., 2019) under

123 default settings other than the clock model being changed to the relaxed log normal model, which showed

124 the highest likelihood value according to the model comparison program compiled in BEAST2 (Drummond

125 et. al., 2006). Posterior probability (PP) on each branch was calculated summarizing four independent 10

126 million MCMC simulations.

127

128 Statistical analyses

129 To clarify the relationships between (1) symbiont lineages and host species, and (2) symbiont lineages and

130 host microhabitats, Fisher's exact test was conducted for the compositions of genotype for ITS-rDNA

131 region and monophyletic clades for $\mathrm{psbA}^{\mathrm{ncr}}$ forward and reverse regions. It should be noted that host

132 microhabitat was restricted by host species for $P$. sp. yoron and $P$. mutuki, and thus we only targeted $P$.

133 tuberculosa for these analyses (aim 2 above) When significance was detected in Fisher's exact test,

134 Cramér's coefficient of association (V) was calculated to evaluate which factors (host species or host 135 microhabitat) were strongly associated with each other.

\section{Results}

\section{Sequence alignment}

139 The total number of sequences of Symbiodiniaceae from specimens of the four Palythoa species obtained 140 in this study was 98 sequences for the ITS-rDNA region (513-773 bp), 40 sequences for the psbA ${ }^{\text {ncr }}$ forward 141 region (330-547 bp), and 41 sequences for the $\mathrm{psbA}^{\mathrm{ncr}}$ reverse region (352-494 bp). As the primer set for $142 \mathrm{psbA}^{\mathrm{ncr}}$ used in this study did not make a congruent contig, obtained sequences of forward regions and 143 reverse regions were aligned separately (Noda et al., 2017). After alignment, a total of 449 sites with 5 144 parsimony informative (=PI) sites for the ITS-rDNA region, 260 sites with 94 PI sites for the psbA ${ }^{\text {ncr }}$ 145 forward region, and 293 sites with 40 PI sites for the $\mathrm{psbA}^{\text {ncr }}$ reverse region were used for each phylogenetic 146 estimation. 
Barcoding, haplotype network and phylogenetic trees

149 As the result of BLAST searches, all query sequences of the ITS-rDNA region ( $\mathrm{n}=98)$ were confirmed as

150 belonging to the genus Cladocopium. Seventeen ITS-rDNA unique sequences (=genotypes) were observed

151 in TCS network, with most of the sequences belonging to one of major three ITS-rDNA genotypes (Fig. 3,

152 Table S1). No significant clade was detected for the ITS-rDNA phylogenetic tree (Fig. S1). Summarizing

153 these ITS-rDNA genotypes from the viewpoint of host species, P. tuberculosa possessed mainly

154 Genotype01 ( $\mathrm{n}=20)$ followed by Genotype02 $(\mathrm{n}=7)$, and $P$. sp. yoron also possessed mainly Genotype01

$155(\mathrm{n}=20)$ followed by Genotype03 $(\mathrm{n}=8)$ (see details in Table S1). On the other hand, P. mutuki possessed

156 mainly Genotype02 (n=13) with a few Genotype01 (n=3) and Genotype03 $(\mathrm{n}=2)$. Although the number of

157 specimens examined was smaller $(\mathrm{n}=6)$ than those the other species, $P$. aff. mutuki also possessed mainly

158 Genotype01 $(\mathrm{n}=5)$.

159

160 In contrast, phylogenetic trees generated from $\mathrm{psbA}^{\mathrm{ncr}}$ regions had a higher resolution. Two monophyletic 161 clades were well supported by bootstrap values and posterior probability in both forward (Fig. 4 clf1,

$162 \mathrm{ML}=100, \mathrm{NJ}=100, \mathrm{PP}=1$ and $c l f 2, \mathrm{ML}=100, \mathrm{NJ}=100, \mathrm{PP}=1$ ) and reverse trees (Fig. 5 clr1 and clr2, $163 \mathrm{ML}=100, \mathrm{NJ}=100, \mathrm{PP}=1)$. Summarizing these Symbiodiniaceae lineages from the viewpoint of host 164 species, $P$. tuberculosa inhabiting the reef edge possessed $c l f 1 /$ clrl lineage $(\mathrm{n}=7 / 5)$ and one specimen 165 inhabiting at the backreef moat possessed clf2/clr2 lineage. Palythoa sp. yoron inhabiting at the backreef 166 moat possessed mainly $\operatorname{clfl} / \operatorname{clrl}(\mathrm{n}=9 / 13)$, however, approximately one third of specimens $(\mathrm{n}=5)$ possessed 167 other lineages. On the other hand, $P$. mutuki inhabiting the reef flat possessed mainly $c l f 2 / c l r 2(\mathrm{n}=8 / 8)$ other 168 than two specimens that possessed $c l f 1 / c l r 1$. Unfortunately, as most of $P$. aff. mutuki specimens were not 169 amplified by this primer set, we could only obtain phylogenetic information on one specimen which 170 possessed the same lineage as $P$. sp. yoron (C24ToKa-PF) for the forward region and $c l r 1$ for the reverse 171 region.

Relationships among symbiont genotype/lineages, host species and host microhabitats

174 From the results of Fisher's Exact test, significant differences were detected in all combinations, i.e. ITS175 rDNA genotype and host species $(\mathrm{p}<0.01)$, $\mathrm{psbA}^{\mathrm{ncr}}$ forward lineages and host species $(\mathrm{p}<0.01), \mathrm{psbA}^{\mathrm{ncr}}$ 176 reverse lineages and host species $(\mathrm{p}<0.01)$, and ITS-rDNA genotype and host microhabitats for $P$. 177 tuberculosa $(\mathrm{p}<0.05)$ (Table 2). In other words, it was shown that Symbiodiniaceae lineages and host 178 species were not independent, nor were Symbiodiniaceae lineages and host microhabitats for $P$. 179 tuberculosa. The effective dose calculated by Cramér's coefficient of association (V) was largest between 
180 host species and $\mathrm{psbA}^{\text {ncr }}$ forward/reverse lineages ( $\mathrm{V}=0.786, \mathrm{~V}=0.682$, respectively), and moderate for the

181 other combinations (host species and ITS-rDNA genotypes, V=0.477; host microhabitats and ITS-rDNA

182 genotypes).

183

\section{Discussion}

185

Symbiodiniaceae genotype/lineage and host species

187 The development of molecular markers such as $\mathrm{psbA}^{\text {ncr }}$ that have higher resolution than commonly used

$18818 \mathrm{~S}$ or ITS ribosomal DNA markers has helped unveil a more detailed picture of the genetic diversity of 189 Symbiodiniaceae (Takishita et al., 2003; LaJeunesse \& Thornhill, 2011; LaJeunesse et al., 2018) (but see 190 also Hume et al., (2019) who utilized intragenomic variation of ITS2 to resolve genetic delineations). 191 Accordingly, host species biodiversity has been discovered from the initial observation of differences of 192 Symbiodiniaceae phylotypes in some cnidarian species (e.g. gorgonian Eunicea flexuosa, Prada et al., 2014; 193 scleractinian coral Seriatopora hystrix, Warner, Oppen \& Willis, 2015).

From the results of Mizuyama, Masucci \& Reimer (2018), none of the four molecular markers utilized could clearly delineate four Palythoa species, although they could delineate two closely related species groups composed of $P$. tuberculosa - P. sp. yoron and P. mutuki - P. aff. mutuki. These previous results seem to be reflected in the results in the current study of Symbiodiniaceae genotypes of ITS-rDNA and lineages of $\mathrm{psbA}^{\mathrm{ncr}}$ regions. Palythoa tuberculosa and $P$. sp. yoron mostly shared the same symbiont genotype (Genotype01); nevertheless, they also partially shared the other genotypes with P. mutuki (Genotype02 and Genotype03). With regard to $\mathrm{psbA}^{\text {ncr }}$ lineages, even though the delineation of species groups between $P$. tuberculosa - P. sp. yoron and P. mutuki were shown more clearly, they were not divided completely. The situation requires further investigation via obtaining more $P$. aff. mutuki specimens' $\mathrm{psbA}^{\mathrm{ncr}}$ sequences. Unfortunately, in the current study, despite much searching, we could not find large may have been strongly affected by the bleaching events of 2016 and 2017 observed in southern Japan 208 (Masucci et al., 2019).

211 From the results of the phylogenetic analyses, three microhabitats were not exclusively allocated in distinct 
212 Symbiodiniaceae genotypes or monophyletic clades, but the ratios of different genotypes were significantly

213 different for P. tuberculosa. Regarding P. tuberculosa, Symbiodiniaceae Genotype01 was mostly detected

214 on the reef edge and reef flat, while Genotype02 was mainly observed in the backreef moat. Although there

215 were not enough samples to conduct statistical examinations of $P$. sp. yoron and $P$. mutuki due to their

216 habitat specificity, Genotype02 and clf2/clr2 were detected mainly on the reef flat, while Genotype01 and

217 clfl/clrl were observed from all three environments.

218

219 It has been reported that zoantharian species with different symbiotic genotypes show species-specific 220 photosynthetic responses against seawater temperature and $p \mathrm{CO}_{2}$ (Graham \& Sanders 2016; Reimer et al., 221 2017b; Wee, Kurihara \& Reimer, 2019). Although the four Palythoa species in this study occurred 222 sympatrically on one reef, the environmental conditions in a reef can be quite different according to small223 scale geographical features. Seawater temperatures on reef flats frequently reach near $40^{\circ} \mathrm{C}$ (Achituv and 224 Dubinsky 1990). In enclosed reefs, seawater temperatures and $p \mathrm{CO}_{2}$ show higher variations than those in 225 exposed reefs (Suzuki, Nakamori \& Kayanne, 1995; Fitt et al., 2001). Thus, the relationship between 226 Symbiodiniaceae and host Palythoa species may change among different microhabitats in a reef area, 227 facilitating ecological divergence of Palythoa species within a narrow geographic range.

228

229

Although a previous molecular study could not distinguish the boundaries among these Palythoa species (Mizuyama, Masucci \& Reimer, 2018), it is suggested by our results that these species are ecologically divergent, and physiological differences within Symbiodiniaceae species may contribute to their ecological adaptation. In fact, Howells et al. (2012) reported that Cladocopium C1 in Acropora tenuis showed different physiological responses between northern and southern populations in the Great Barrier Reef. Considering that Cladocopium contains various species distinguished by differences of only a few bp (Thornhill et al., 2014), meta-barcoding analyses via next-generation sequencing would be necessary to further understand the detailed relationship between Symbiodiniaceae and Palythoa species complex.

237

\section{Conclusions}

239 We succeeded in obtaining genotypic data of Symbiodiniaceae from four putative Palythoa species and 240 detected micro-scale geographic variations of the symbiotic algae among these species within a single coral 241 reef. Our results suggest that ecological divergence among Palythoa species may be related to differences

242 in Symbiodiniaceae diversities among microhabitats, even within a narrow reef area. More powerful genetic 243 data such as that generated by next-generation sequencing could provide us with additional understanding 
244 on how neighboring Palythoa species have co-evolved with Symbiodiniaceae among the different 245 microhabitats in a reef.

246

247

\section{Acknowledgements}

248 This study was funded by the research support programs of the National Institute of Advanced Industrial 249 Science and Technology to MM.

250

251

\section{References}

252

Achituv, Y., \& Dubinsky, Z. (1990). Evolution and zoogeography of coral reefs ecosystems of the world.

253

Coral Reefs. Elsevier, Amsterdam.

254

255

256

257

258

259

260

261

262

263

264

265

266

267

268

269

270

271

272

273

274

275 321-330.

Albinsky, D., Wham, D., Shinzato, N., \& Reimer, J. D. (2018). Population connectivity in the common reef zoantharian Zoanthus sansibaricus (Anthozoa: Hexacorallia) in southern Japan. Zoological Science, 35(4),

Baillie, B. K., Belda-Baillie, C. A., \& Maruyama, T. (2000). Conspecificity and Indo-Pacific distribution of Symbiodinium genotypes (Dinophyceae) from giant clams. Journal of Phycology, 36(6), 1153-1161.

Baker, A. C. (2003). Flexibility and specificity in coral-algal symbiosis: diversity, ecology, and biogeography of Symbiodinium. Annual Review of Ecology, Evolution, and Systematics, 34(1), 661-689.

Bongaerts, P., Riginos, C., Ridgway, T., Sampayo, E. M., van Oppen, M. J., Englebert, N., Vermeulen, F., \& Hoegh-Guldberg, O. (2010). Genetic divergence across habitats in the widespread coral Seriatopora hystrix and its associated Symbiodinium. PLoS one, 5(5), e10871.

Bouckaert, R., Vaughan, T. G., Barido-Sottani, J., Duchêne, S., Fourment, M., Gavryushkina, A., Heled, J., Jones, G., Kühnert, D., Maio, N., Matschiner, M., Mendes, F. K., Müller, N. F., Ogilvie, H. A., Plessis, L., Popinga, A., Rambaut, A., Rasmussen, D., Siveroni, I., Suchard, M. A., Wu, C. H., Xie, D., Zhang, C., Stadler, T., \& Drummond, A. J. (2019). BEAST 2.5: An advanced software platform for Bayesian evolutionary analysis. PLoS Computational Biology, 15(4), e1006650.

Burnett, W. J., Benzie, J. A. H, Beardmore, J. A., \& Ryland, J. S. (1994). High genetic variability and 
276

277

278

279

280

281

282

283

284

285

286

287

288

289

290

291

292

293

294

295

296

297

298

299

300

301

302

303

304

305

306

307

patchiness in a common Great Barrier Reef zoanthid (Palythoa caesia). Marine Biology, 121(1), 153-160.

Clement, M. J., Snell, Q., Walker, P., Posada, D., \& Crandall, K. A. (2002). TCS: estimating gene genealogies. Proc 16th Int Parallel Distrib Process Symp 2:184.

Drummond, A. J., Ho, S. Y., Phillips, M. J., \& Rambaut, A. (2006). Relaxed phylogenetics and dating with confidence. PLoS Biology, 4(5), e88.

Fitt, W. K., Brown, B. E., Warner, M. E., \& Dunne, R. P. (2001). Coral bleaching: interpretation of thermal tolerance limits and thermal thresholds in tropical corals. Coral Reefs, 20(1), 51-65.

Graham, E. R., \& Sanders, R. W. (2016). Species-specific photosynthetic responses of symbiotic zoanthids to thermal stress and ocean acidification. Marine Ecology, 37(2), 442-458.

Hall, T. A. (1999). BioEdit: a user-friendly biological sequence alignment editor and analysis program for Windows 95/98/NT. Nucleic Acids Symposium Series 41:95-98.

Howells, E. J., Beltran, V. H., Larsen, N. W., Bay, L. K., Willis, B. L., \& Van Oppen, M. J. H. (2012). Coral thermal tolerance shaped by local adaptation of photosymbionts. Nature Climate Change, 2(2), 116.

Hume, B. C. C., Smith, E. G., Ziegler, M., Warrington, H. J. M., Burt, J. A., LaJeunesse, T. C., Wiedenmann, J., \& Voolstra, C. R. (2019). SymPortal: A novel analytical framework and platform for coral algal symbiont next - generation sequencing ITS2 profiling. Molecular Ecology Resources, 1-18.

Irei, Y., Nozawa, Y., \& Reimer, J. D. (2011). Distribution patterns of five zoanthid species in Okinawa Island, Japan. Zoological Studies, 50(4), 426-433.

Kumar S., Stecher G., Li M., Knyaz C., \& Tamura K. (2018). MEGA X: Molecular Evolutionary Genetics Analysis across computing platforms. Molecular Biology and Evolution 35:1547-1549.

LaJeunesse, T. C., \& Thornhill, D. J. (2011). Improved resolution of reef-coral endosymbiont (Symbiodinium) species diversity, ecology, and evolution through psbA non-coding region genotyping. 
308

309

310

311

312

313

314 Leigh, J. W., \& Bryant, D. (2015). popart: full - feature software for haplotype network construction.

315

316

317

318

319

320

321

322

323

324

325

326

327

328

329

330

331

332

333

334

335

336

337

338

339

PLoS One, 6(12), e29013.

LaJeunesse, T. C., Parkinson, J. E., Gabrielson, P. W., Jeong, H. J., Reimer, J. D., Voolstra, C. R., \& Santos, S. R. (2018). Systematic revision of Symbiodiniaceae highlights the antiquity and diversity of coral endosymbionts. Current Biology, 28(16), 2570-2580.

Methods in Ecology and Evolution, 6(9), 1110-1116.

Masucci, G. D., Biondi, P., Negro, E., \& Reimer, J. D. (2019). After the long summer: Death and survival of coral communities in the shallow waters of Kume Island, from the Ryukyu Archipelago. Regional Studies in Marine Science, 28, 100578.

Mizuyama, M., Masucci, G. D., \& Reimer, J. D. (2018). Speciation among sympatric lineages in the genus Palythoa (Cnidaria: Anthozoa: Zoantharia) revealed by morphological comparison, phylogenetic analyses and investigation of spawning period. PeerJ, 6, e5132.

Moore, R. B., Ferguson, K. M., Loh, W. K., Hoegh-Guldberg, O., \& Carter, D. A. (2003). Highly organized structure in the non-coding region of the psbA minicircle from clade C Symbiodinium. International Journal of Systematic and Evolutionary Microbiology, 53(6), 1725-1734.

Noda, H., Parkinson, J. E., Yang, S. Y., \& Reimer, J. D. (2017). A preliminary survey of zoantharian endosymbionts shows high genetic variation over small geographic scales on Okinawa-jima Island, Japan. PeerJ, 5, e3740.

Pinzon, J. H., \& LaJeunesse, T. C. (2011). Species delimitation of common reef corals in the genus Pocillopora using nucleotide sequence phylogenies, population genetics and symbiosis ecology. Molecular Ecology, 20(2), 311-325.

Prada, C., McIlroy, S. E., Beltrán, D. M., Valint, D. J., Ford, S. A., Hellberg, M. E., \& Coffroth, M. A. (2014). Cryptic diversity hides host and habitat specialization in a gorgonian - algal symbiosis. Molecular ecology, 23(13), 3330-3340. 
341 Reimer, J. D., Santos, M. E. A., Kise, H., Neo, M. L., Chen, C. A., \& Soong, K. (2017a). Diversity of 342 Zoantharia (Anthozoa: Hexacorallia) at Dongsha Atoll in the South China Sea. Regional Studies in Marine 343 Science, 12, 49-57.

344

345 Reimer, J. D., Herrera, M., Gatins, R., Roberts, M. B., Parkinson, J. E., \& Berumen, M. L. (2017b).

346 Latitudinal variation in the symbiotic dinoflagellate Symbiodinium of the common reef zoantharian

347 Palythoa tuberculosa on the Saudi Arabian coast of the Red Sea. Journal of Biogeography, 44(3), 661-673. 348

Reimer, J. D., Takishita, K., \& Maruyama, T. (2006). Molecular identification of symbiotic dinoflagellates (Symbiodinium spp.) from Palythoa spp. (Anthozoa: Hexacorallia) in Japan. Coral Reefs, 25(4), 521-527.

351

352

Santos, M. E. A., Kitahara, M. V., Lindner, A., \& Reimer, J. D. (2016). Overview of the order Zoantharia 354

Shiroma, E., \& Reimer, J.D. (2010). Investigations into the reproductive patterns, ecology, and morphology in the zoanthid genus Palythoa (Cnidaria: Anthozoa: Hexacorallia) in Okinawa, Japan. Zoological Studies. 49(2), 182-194.

358

Suzuki, A., Nakamori, T., \& Kayanne, H. (1995). The mechanism of production enhancement in coral reef carbonate systems: model and empirical results. Sedimentary Geology, 99(3-4), 259-280.

361

Takishita, K., Ishikura, M., Koike, K., \& Maruyama, T. (2003). Comparison of phylogenies based on nuclear-encoded SSU rDNA and plastid-encoded psbA in the symbiotic dinoflagellate genus Symbiodinium. Phycologia, 42(3), 285-291.

365 dominate the adaptive radiation of reef coral endosymbionts. Evolution, 68(2), 352-367.

Torda, G., Donelson, J. M., Aranda, M., Barshis, D. J., Bay, L., Berumen, M. L., Bourne, D. G., Cantin, 
372 Rapid adaptive responses to climate change in corals. Nature Climate Change, 7(9), 627.

373

374 Warner, P. A., van Oppen, M. J., \& Willis, B. L. (2015). Unexpected cryptic species diversity in the

375 widespread coral Seriatopora hystrix masks spatial - genetic patterns of connectivity. Molecular Ecology, 376 24(12), 2993-3008.

377

378 Wee, H. B., Kurihara, H., \& Reimer, J. D. (2019). Reduced Symbiodiniaceae diversity in Palythoa 379 tuberculosa at a heavily acidified coral reef. Coral Reefs, 38(2), 311-319.

380

381

Winters, G., Beer, S., Zvi, B. B., Brickner, I., \& Loya, Y. (2009). Spatial and temporal photoacclimation of 382 Stylophora pistillata: zooxanthella size, pigmentation, location and clade. Marine Ecology Progress Series, 383 $384,107-119$.

384

385

Figure legends

386

Figure 1. Location of Tokunoshima Island and the sampling site (arrow in inset) for the Palythoa specimens

in this study. Map data: GeoLite2 data created by MaxMind in the Generic Mapping Tools (GMT v5.4.5)

388 software package.

389

Figure 2. Landscape of the coral reef flat at the study site and in situ images of Palythoa species used in this study. A, Satellite image of the reef area obtained by Google Earth; B, reef edge; C, P. tubeculosa; D, reef flat 1; E, P. tuberculosa; F, reef flat 2; G, P. mutuki; H, backreef moat; I, P. sp. yoron. Map data: Google, Maxar Technologies. Scale bars in C, E, G, and I are $10 \mathrm{~cm}$.

Figure 3. Haplotype network tree constructed with nuclear ITS-rDNA region alignment using TCS networks method. Scale represents number of sequences with circle sizes proportional to haplotype green, $P$. aff. mutuki.

Figure 4. Molecular phylogenetic tree of Symbiodiniaceae of Palythoa species using mitochondrial psbA ${ }^{\text {ncr }}$ forward region. Bootstrap values of maximum likelihood (ML) and neighbor joining (NJ) methods, and posterior probability (PP) are shown more than $70 \%$ for $\mathrm{ML}$ and $\mathrm{NJ}$, and more than 0.95 for PP at the nodes, 
404 Palythoa species and their habitats, respectively: red, $P$. tuberculosa; yellow, $P$. sp. yoron; blue, $P$. mutuki; 405 green, $P$. aff. mutuki; circle in pink, reef edge; triangle in purple, reef flat; square in orange, backreef moat. 406

407 Figure 5. Molecular phylogenetic tree of Symbiodiniaceae of Palythoa species using mitochondrial psbA ${ }^{\text {ncr }}$ 408 reverse region. Bootstrap values of maximum likelihood (ML) and neighbor joining (NJ) methods, and 409 posterior probability (PP) are shown more than $70 \%$ for ML and $\mathrm{NJ}$, and more than 0.95 for PP at the nodes, 410 respectively. Scale bars indicate substitutions per site. Colored letters and colored diagrams represent 411 Palythoa species and their habitats, respectively: red, P. tuberculosa; yellow, P. sp. yoron; blue, P. mutuki; 412 green, $P$. aff. mutuki; circle in pink, reef edge; triangle in purple, reef flat; square in orange, backreef moat. 413

414 Figure S1. Molecular phylogenetic tree of Symbiodiniaceae of Palythoa species using sequences of the 415 nuclear ITS-rDNA region. Shaded boxes represent three main genotypes occupying most sequences from 416 four Palythoa species. Bootstrap values of maximum likelihood (ML) and neighbor joining (NJ) methods, 417 and posterior probability (PP) are shown more than $70 \%$ for ML and NJ, and more than 0.95 for PP at the 418 nodes, respectively. Scale bars indicate substitutions per site. Colored letters and colored diagrams represent 419 Palythoa species and their habitats, respectively: red, P. tuberculosa; yellow, P. sp. yoron; blue, P. mutuki; 420 green, $P$. aff. mutuki; circle in pink, reef edge; triangle in purple, reef flat; square in orange, backreef moat. 
Table $\mathbf{1}$ (on next page)

Specimen list. 
Table 1 Specimen list.

\begin{tabular}{|c|c|c|c|c|c|c|c|}
\hline Specimen ID & Location / Region & Spiecies ID & Date $(\mathrm{m} / \mathrm{d} / \mathrm{y})$ & Environment & Accession no. of ITS & Accession no. of psbA-F & Accession no. of psbA-R \\
\hline A01PtToKa & Kaminomine / Tokunoshima & Palythoa tuberculosa & Jun 2. 2019 & Reef edge & MN654209 & MN654185 & - \\
\hline A02PtToKa & Kaminomine / Tokunoshima & Palythoa tuberculosa & Jun 2. 2019 & Reef edge & MN654210 & MN654184 & MN654134 \\
\hline A03PtToKa & Kaminomine / Tokunoshima & Palythoa tuberculosa & Jun 2. 2019 & Reef edge & MN654211 & - & - \\
\hline A04PtToKa & Kaminomine / Tokunoshima & Palythoa tuberculosa & Jun 2. 2019 & Reef edge & MN654212 & MN654186 & MN654135 \\
\hline A05PtToKa & Kaminomine / Tokunoshima & Palythoa tuberculosa & Jun 2. 2019 & Reef edge & MN654213 & MN654187 & MN654136 \\
\hline A06PtToKa & Kaminomine / Tokunoshima & Palythoa tuberculosa & Jun 2. 2019 & Reef edge & MN654214 & MN654188 & - \\
\hline A07PtToKa & Kaminomine / Tokunoshima & Palythoa tuberculosa & Jun 2. 2019 & Reef edge & MN654215 & MN654189 & MN654137 \\
\hline A08PtToKa & Kaminomine / Tokunoshima & Palythoa tuberculosa & Jun 2. 2019 & Reef edge & MN654216 & MN654190 & MN654138 \\
\hline A09PtToKa & Kaminomine / Tokunoshima & Palythoa tuberculosa & Jun 2. 2019 & Reef edge & MN654217 & - & - \\
\hline A11PtToKa & Kaminomine / Tokunoshima & Palythoa tuberculosa & Jun 2. 2019 & Reef flat & MN654218 & MN654191 & MN654139 \\
\hline A12PtToKa & Kaminomine / Tokunoshima & Palythoa tuberculosa & Jun 2. 2019 & Reef flat & MN654219 & MN654192 & MN654140 \\
\hline A13PtToKa & Kaminomine / Tokunoshima & Palythoa tuberculosa & Jun 2. 2019 & Reef flat & MN654220 & MN654193 & - \\
\hline A14PtToKa & Kaminomine / Tokunoshima & Palythoa tuberculosa & Jun 2. 2019 & Reef flat & MN654221 & - & - \\
\hline A15PtToKa & Kaminomine / Tokunoshima & Palythoa tuberculosa & Jun 2. 2019 & Reef flat & MN654222 & - & - \\
\hline A16PtToKa & Kaminomine / Tokunoshima & Palythoa tuberculosa & Jun 2. 2019 & Reef flat & MN654223 & MN654194 & MN654141 \\
\hline A17PtToKa & Kaminomine / Tokunoshima & Palythoa tuberculosa & Jun 2. 2019 & Reef flat & MN654224 & - & - \\
\hline A18PtToKa & Kaminomine / Tokunoshima & Palythoa tuberculosa & Jun 2. 2019 & Reef flat & MN654225 & MN654195 & MN654142 \\
\hline A19PtToKa & Kaminomine / Tokunoshima & Palythoa tuberculosa & Jun 2. 2019 & Reef flat & MN654226 & MN654198 & - \\
\hline A20PtToKa & Kaminomine / Tokunoshima & Palythoa tuberculosa & Jun 2. 2019 & Reef flat & MN654227 & - & - \\
\hline A21PtToKa & Kaminomine / Tokunoshima & Palythoa tuberculosa & Jun 2. 2019 & Backreef moat & MN654228 & MN654169 & MN654159 \\
\hline A22PtToKa & Kaminomine / Tokunoshima & Palythoa tuberculosa & Jun 2. 2019 & Backreef moat & MN654229 & - & - \\
\hline A24PtToKa & Kaminomine / Tokunoshima & Palythoa tuberculosa & Jun 2. 2019 & Backreef moat & MN654230 & - & MN654143 \\
\hline A25PtToKa & Kaminomine / Tokunoshima & Palythoa tuberculosa & Jun 2. 2019 & Backreef moat & MN654231 & - & - \\
\hline A26PtToKa & Kaminomine / Tokunoshima & Palythoa tuberculosa & Jun 2. 2019 & Backreef moat & MN654232 & - & - \\
\hline A27PtToKa & Kaminomine / Tokunoshima & Palythoa tuberculosa & Jun 2. 2019 & Backreef moat & MN654233 & - & - \\
\hline A28PtToKa & Kaminomine / Tokunoshima & Palythoa tuberculosa & Jun 2. 2019 & Backreef moat & MN654234 & - & - \\
\hline A29PtToKa & Kaminomine / Tokunoshima & Palythoa tuberculosa & Jun 2. 2019 & Backreef moat & MN654235 & - & - \\
\hline A30PtToKa & Kaminomine / Tokunoshima & Palythoa tuberculosa & Jun 2. 2019 & Backreef moat & MN654236 & - & - \\
\hline
\end{tabular}




\begin{tabular}{|c|c|c|c|c|c|c|c|}
\hline B01PmToKa & Kaminomine / Tokunoshima & Palythoa mutuki & Jun 2. 2019 & Reef flat & MN654237 & - & - \\
\hline B02PmToKa & Kaminomine / Tokunoshima & Palythoa mutuki & Jun 2. 2019 & Reef flat & MN654238 & MN654199 & MN654144 \\
\hline B03PmToKa & Kaminomine / Tokunoshima & Palythoa mutuki & Jun 2. 2019 & Reef flat & MN654239 & - & - \\
\hline B04PmToKa & Kaminomine / Tokunoshima & Palythoa mutuki & Jun 2. 2019 & Reef flat & MN654240 & - & - \\
\hline B05PmToKa & Kaminomine / Tokunoshima & Palythoa mutuki & Jun 2. 2019 & Reef flat & MN654241 & - & MN654145 \\
\hline B06PmToKa & Kaminomine / Tokunoshima & Palythoa mutuki & Jun 2. 2019 & Reef flat & MN654242 & MN654170 & MN654160 \\
\hline B07PmToKa & Kaminomine / Tokunoshima & Palythoa mutuki & Jun 2. 2019 & Reef flat & MN654243 & - & MN654161 \\
\hline B08PmToKa & Kaminomine / Tokunoshima & Palythoa mutuki & Jun 2. 2019 & Reef flat & MN654244 & MN654171 & MN654162 \\
\hline B09PmToKa & Kaminomine / Tokunoshima & Palythoa mutuki & Jun 2. 2019 & Reef flat & MN654245 & - & - \\
\hline B11PmToKa & Kaminomine / Tokunoshima & Palythoa mutuki & Jun 2. 2019 & Reef flat & MN654246 & - & - \\
\hline B12PmToKa & Kaminomine / Tokunoshima & Palythoa mutuki & Jun 3. 2019 & Reef flat & MN654247 & MN654172 & - \\
\hline B13PmToKa & Kaminomine / Tokunoshima & Palythoa mutuki & Jun 3. 2019 & Reef flat & MN654248 & - & - \\
\hline B14PmToKa & Kaminomine / Tokunoshima & Palythoa mutuki & Jun 3. 2019 & Reef flat & MN654249 & MN654173 & - \\
\hline B15PmToKa & Kaminomine / Tokunoshima & Palythoa mutuki & Jun 3.2019 & Reef flat & MN654250 & - & - \\
\hline B16PmToKa & Kaminomine / Tokunoshima & Palythoa mutuki & Jun 3. 2019 & Reef flat & MN654251 & - & - \\
\hline B17PmToKa & Kaminomine / Tokunoshima & Palythoa mutuki & Jun 3. 2019 & Reef flat & MN654252 & MN654174 & MN654163 \\
\hline B18PmToKa & Kaminomine / Tokunoshima & Palythoa mutuki & Jun 3. 2019 & Reef flat & MN654253 & MN654200 & - \\
\hline B20PmToKa & Kaminomine / Tokunoshima & Palythoa mutuki & Jun 3. 2019 & Reef flat & MN654254 & - & - \\
\hline B21PmToKa & Kaminomine / Tokunoshima & Palythoa mutuki & Jun 3.2019 & Reef flat & MN654255 & - & - \\
\hline $\mathrm{B} 22 \mathrm{PmToKa}$ & Kaminomine / Tokunoshima & Palythoa mutuki & Jun 3. 2019 & Reef flat & MN654256 & - & - \\
\hline B23PmToKa & Kaminomine / Tokunoshima & Palythoa mutuki & Jun 3. 2019 & Reef flat & MN654257 & - & - \\
\hline B24PmToKa & Kaminomine / Tokunoshima & Palythoa mutuki & Jun 3.2019 & Reef flat & MN654258 & MN654175 & MN654164 \\
\hline B25PmToKa & Kaminomine / Tokunoshima & Palythoa mutuki & Jun 3. 2019 & Reef flat & - & MN654176 & MN654165 \\
\hline B26PmToKa & Kaminomine / Tokunoshima & Palythoa mutuki & Jun 3.2019 & Reef flat & MN654259 & - & MN654166 \\
\hline B28PmToKa & Kaminomine / Tokunoshima & Palythoa mutuki & Jun 3.2019 & Reef flat & - & MN654177 & MN654167 \\
\hline С01РyToKa & Kaminomine / Tokunoshima & Palythoa sp. yoron & Jun 2. 2019 & Backreef moat & MN654260 & - & - \\
\hline С02РyТoKa & Kaminomine / Tokunoshima & Palythoa sp. yoron & Jun 2. 2019 & Backreef moat & MN654261 & - & - \\
\hline C03РyToKa & Kaminomine / Tokunoshima & Palythoa sp. yoron & Jun 2. 2019 & Backreef moat & MN654262 & - & - \\
\hline C04PyToKa & Kaminomine / Tokunoshima & Palythoa sp. yoron & Jun 2. 2019 & Backreef moat & MN654263 & - & - \\
\hline C05PyToKa & Kaminomine / Tokunoshima & Palythoa sp. yoron & Jun 2. 2019 & Backreef moat & MN654264 & - & - \\
\hline
\end{tabular}




\begin{tabular}{|c|c|c|c|c|c|c|c|}
\hline С06РyToKa & Kaminomine / Tokunoshima & Palythoa sp. yoron & Jun 2. 2019 & Backreef moat & MN654265 & - & - \\
\hline C07PyToKa & Kaminomine / Tokunoshima & Palythoa sp. yoron & Jun 2. 2019 & Backreef moat & MN654266 & - & - \\
\hline C08РyToKa & Kaminomine / Tokunoshima & Palythoa sp. yoron & Jun 2. 2019 & Backreef moat & MN654267 & - & - \\
\hline С09РуТоКа & Kaminomine / Tokunoshima & Palythoa sp. yoron & Jun 2. 2019 & Backreef moat & MN654268 & - & - \\
\hline C10РуТоКа & Kaminomine / Tokunoshima & Palythoa sp. yoron & Jun 2. 2019 & Backreef moat & MN654269 & - & - \\
\hline C11PyToKa & Kaminomine / Tokunoshima & Palythoa sp. yoron & Jun 2. 2019 & Backreef moat & MN654270 & - & - \\
\hline C12РyToKa & Kaminomine / Tokunoshima & Palythoa sp. yoron & Jun 2. 2019 & Backreef moat & MN654271 & MN654201 & MN654146 \\
\hline C13РуТоКа & Kaminomine / Tokunoshima & Palythoa sp. yoron & Jun 2. 2019 & Backreef moat & MN654272 & - & - \\
\hline C14РyToKa & Kaminomine / Tokunoshima & Palythoa sp. yoron & Jun 2. 2019 & Backreef moat & MN654273 & MN654179 & MN654147 \\
\hline C15РyToKa & Kaminomine / Tokunoshima & Palythoa sp. yoron & Jun 2. 2019 & Backreef moat & MN654274 & MN654180 & - \\
\hline C16РyToKa & Kaminomine / Tokunoshima & Palythoa sp. yoron & Jun 2. 2019 & Backreef moat & MN654275 & MN654202 & MN654148 \\
\hline C17РуToKa & Kaminomine / Tokunoshima & Palythoa sp. yoron & Jun 2. 2019 & Backreef moat & MN654276 & MN654203 & MN654149 \\
\hline C18РyToKa & Kaminomine / Tokunoshima & Palythoa sp. yoron & Jun 2. 2019 & Backreef moat & MN654277 & - & MN654168 \\
\hline C19РуТоКа & Kaminomine / Tokunoshima & Palythoa sp. yoron & Jun 3. 2019 & Backreef moat & MN654278 & - & - \\
\hline С20РyToKa & Kaminomine / Tokunoshima & Palythoa sp. yoron & Jun 3. 2019 & Backreef moat & MN654279 & MN654204 & MN654150 \\
\hline C21PyToKa & Kaminomine / Tokunoshima & Palythoa sp. yoron & Jun 3. 2019 & Backreef moat & MN654280 & MN654205 & MN654151 \\
\hline C22РyToKa & Kaminomine / Tokunoshima & Palythoa sp. yoron & Jun 3. 2019 & Backreef moat & MN654281 & MN654206 & MN654152 \\
\hline C24РуToKa & Kaminomine / Tokunoshima & Palythoa sp. yoron & Jun 3. 2019 & Backreef moat & MN654282 & MN654181 & - \\
\hline C25РyToKa & Kaminomine / Tokunoshima & Palythoa sp. yoron & Jun 3. 2019 & Backreef moat & MN654283 & MN654196 & MN654153 \\
\hline С26РyТoKa & Kaminomine / Tokunoshima & Palythoa sp. yoron & Jun 3. 2019 & Backreef moat & MN654284 & - & MN654154 \\
\hline C27РyToKa & Kaminomine / Tokunoshima & Palythoa sp. yoron & Jun 3. 2019 & Backreef moat & MN654285 & MN654207 & MN654155 \\
\hline С28РyТoKa & Kaminomine / Tokunoshima & Palythoa sp. yoron & Jun 3. 2019 & Backreef moat & MN654286 & - & - \\
\hline С29РуТоКа & Kaminomine / Tokunoshima & Palythoa sp. yoron & Jun 3.2019 & Backreef moat & MN654287 & MN654208 & MN654156 \\
\hline С30РуТоКа & Kaminomine / Tokunoshima & Palythoa sp. yoron & Jun 3. 2019 & Backreef moat & MN654288 & MN654182 & MN654157 \\
\hline 159PamToKa & Kaminomine / Tokunoshima & Palythoa aff. mutuki & July 28. 2010 & In Mizuyama et al., 2018 & MN654300 & - & - \\
\hline 233PamErYa & Yakomo / Okinoerabu & Palythoa aff. mutuki & Jun 17. 2011 & In Mizuyama et al., 2018 & MN654301 & - & - \\
\hline 237PamErSu & Sumiyoshi / Okinoerabu & Palythoa aff. mutuki & Jun 18. 2011 & In Mizuyama et al., 2018 & MN654302 & - & - \\
\hline 248PamToKa & Kaminomine / Tokunoshima & Palythoa aff. mutuki & Jun 21. 2011 & In Mizuyama et al., 2018 & MN654303 & - & - \\
\hline 250PamToKa & Kaminomine / Tokunoshima & Palythoa aff. mutuki & Jun 21. 2011 & In Mizuyama et al., 2018 & MN654304 & MN654183 & MN654131 \\
\hline 328PamOkTe & Teniya / Okinawa & Palythoa aff. mutuki & Apr 5. 2012 & In Mizuyama et al., 2018 & MN654305 & - & - \\
\hline
\end{tabular}




\begin{tabular}{|c|c|c|c|c|c|c|c|}
\hline 364PamOkOk & Oku / Okinawa & Palythoa aff. mutuki & Jun 25. 2012 & In Mizuyama et al., 2018 & MN654306 & - & - \\
\hline 2PtOkOd & Odo / Okinawa & Palythoa tuberculosa & Aug 18. 2009 & In Mizuyama et al., 2018 & MN654289 & - & MN654158 \\
\hline 39PtYoUk & Ukachi / Yoron & Palythoa tuberculosa & Mar 4. 2010 & In Mizuyama et al., 2018 & MN654290 & - & MN654132 \\
\hline 63PtErYa & Yakomo / Okinoerabu & Palythoa tuberculosa & Mar 5. 2010 & In Mizuyama et al., 2018 & MN654291 & - & MN654133 \\
\hline 100PtToKa & Kaminomine / Tokunoshima & Palythoa tuberculosa & Mar 9. 2010 & In Mizuyama et al., 2018 & MN654292 & - & MN654128 \\
\hline 15PyOkOd & Odo / Okinawa & Palythoa sp. yoron & Sep 5. 2009 & In Mizuyama et al., 2018 & MN654297 & - & MN654130 \\
\hline 51PyYoUk & Ukachi(West) / Yoron & Palythoa sp. yoron & Mar 4. 2010 & In Mizuyama et al., 2018 & MN654298 & - & - \\
\hline 85PyErYa & Yakomo / Okinoerabu & Palythoa sp. yoron & Mar 5. 2010 & In Mizuyama et al., 2018 & MN654296 & MN654197 & - \\
\hline 105РуТoКа & Kaminomine / Tokunoshima & Palythoa sp. yoron & Mar 9. 2010 & In Mizuyama et al., 2018 & MN654299 & MN654178 & MN654129 \\
\hline 218PmOkOd & Odo / Okinawa & Palythoa mutuki & May 4. 2011 & In Mizuyama et al., 2018 & MN654294 & - & - \\
\hline 77PmErYa & Yakomo / Okinoerabu & Palythoa mutuki & Mar 5. 2010 & In Mizuyama et al., 2018 & MN654293 & - & - \\
\hline 280PmToKa & Kaminomine / Tokunoshima & Palythoa mutuki & Oct 5. 2011 & In Mizuyama et al., 2018 & MN654295 & - & - \\
\hline
\end{tabular}




\section{Table 2 (on next page)}

Composition of genotype for ITS-rDNA sequences and monophyletic clades for $\mathrm{psbA}^{\text {ncr }}$ sequences of Symbiodiniaceae from Palythoa species used in this study and microenvironments of host habitats.

Significances were tested by Fisher's Exact Test and V value represents Cramer's coefficient of association. 
Table 2. Composition of genotype for ITS-rDNA sequences and monophyletic clades for psbA $^{\text {ncr }}$ sequences of Symbiodiniaceae from Palythoa species used in this study and microenvironments of host habitats. Significances were tested by Fisher's Exact Test and V value represents Cramer's coefficient of association.

\begin{tabular}{|c|c|c|c|c|c|c|c|c|}
\hline \multirow{2}{*}{$\begin{array}{l}\square \\
\square \\
\square\end{array}$} & $\square$ & \multicolumn{3}{|c|}{$\begin{array}{l}\text { Symbiodiniaceae genotype } \\
\text { (ITS-rDNA) }\end{array}$} & \multicolumn{2}{|c|}{$\begin{array}{l}\text { Symbiodiniaceae lineage } \\
\text { (psbA }^{\mathrm{ncr}} \text { forward region) }\end{array}$} & \multicolumn{2}{|c|}{$\begin{array}{l}\text { Symbiodiniaceae lineage } \\
\left(\mathrm{psbA}^{\mathrm{ncr}} \text { reverse region) }\right.\end{array}$} \\
\hline & $\square$ & Genotype01 & Genotype02 & Genotype03 & clf1 & clf2 & $\operatorname{clrl}$ & $\operatorname{clr} 2$ \\
\hline \multirow[t]{5}{*}{ Host species } & P. tuberculosa & 20 & 7 & 0 & 13 & 1 & 13 & 2 \\
\hline & $P . \mathrm{sp}$. yoron & 20 & 1 & 8 & 10 & 0 & 14 & 1 \\
\hline & P. mutuki & 3 & 13 & 2 & 2 & 8 & 2 & 8 \\
\hline & $P$. aff. mutuki & 5 & 1 & 0 & - & - & - & - \\
\hline & Total & 48 & 22 & 10 & 25 & 9 & 29 & 11 \\
\hline$\square$ & $\square$ & \multicolumn{3}{|c|}{$\mathrm{p}<0.01, \mathrm{~V}=0.477$} & $p<0$. & 0.786 & \multicolumn{2}{|c|}{$p<0.01, \mathrm{~V}=0.682$} \\
\hline \multirow{5}{*}{$\begin{array}{l}\text { Host habitats of } \\
\text { P. tuberculosa }\end{array}$} & Reef edge & 8 & 0 & & & & & \\
\hline & Reef flat & 7 & 2 & & & & & \\
\hline & Backreef moat & 2 & 4 & & & & & \\
\hline & Total & 17 & 6 & & & & & \\
\hline & & $\mathrm{p}<0.05$ & $V=0.508$ & $\square$ & & & & \\
\hline
\end{tabular}

Note: $P$. aff. mutuki was removed from statistical analyses of $\mathrm{psbA}^{\mathrm{ncr}}$ region due to its few numbers of specimens. 


\section{Figure 1}

Location of Tokunoshima Island and the sampling site (arrow in inset) for the Palythoa specimens in this study.

Map data: GeoLite2 data created by MaxMind using the Generic Mapping Tools (GMT v5.4.5) software package.

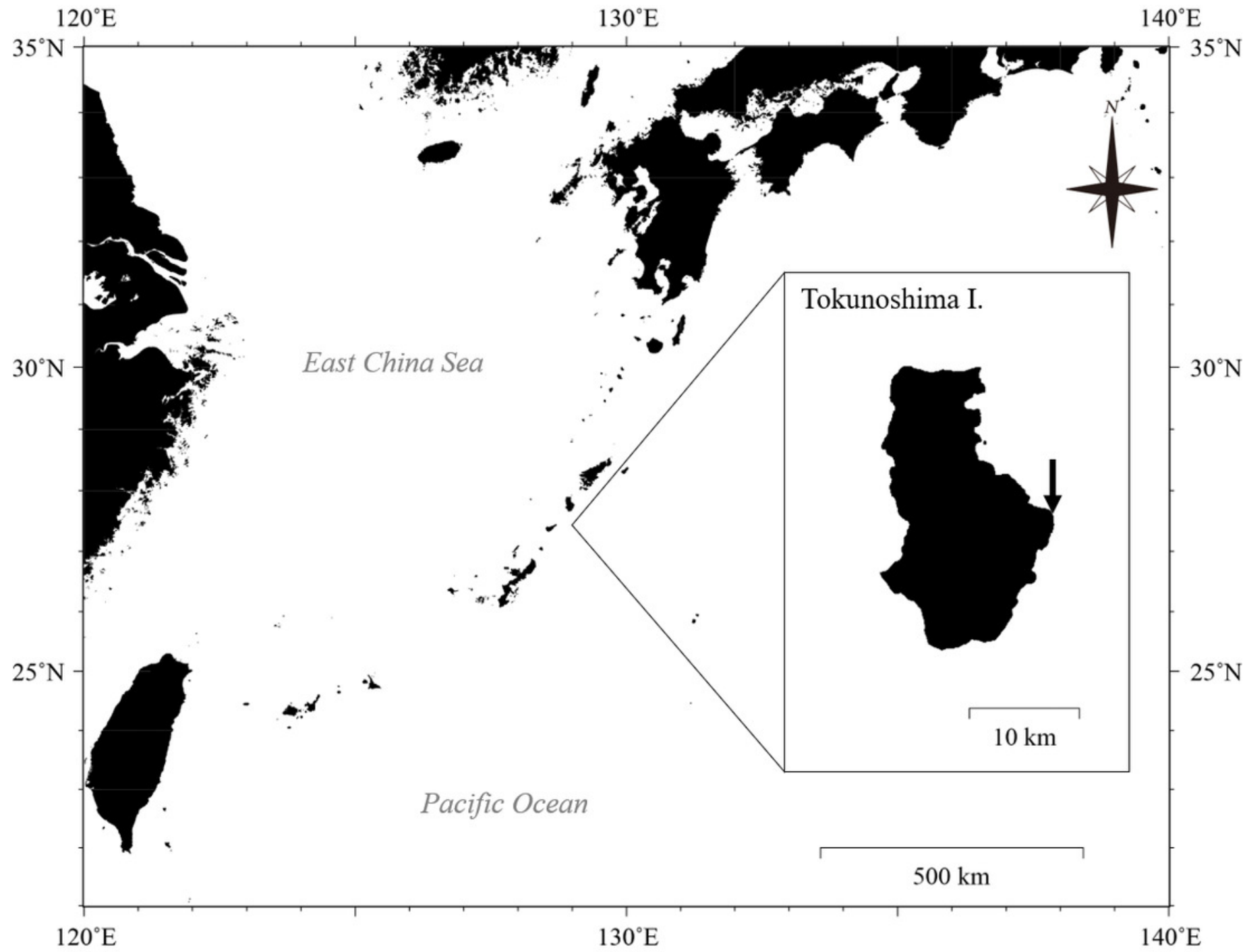


Figure 2

Landscape of the coral reef flat at the study site and in situ images of Palythoa species used in this study.

A, Satellite image of the reef area obtained by Google Earth; B, reef edge; C, P. tubeculosa;

$D$, reef flat 1; E, P. tuberculosa; F, reef flat 2; G, P. mutuki; $\mathrm{H}$, backreef moat; I, $P$. sp. yoron. Map data: Google, Maxar Technologies. Scale bars in C, E, G, and I are $10 \mathrm{~cm}$. 


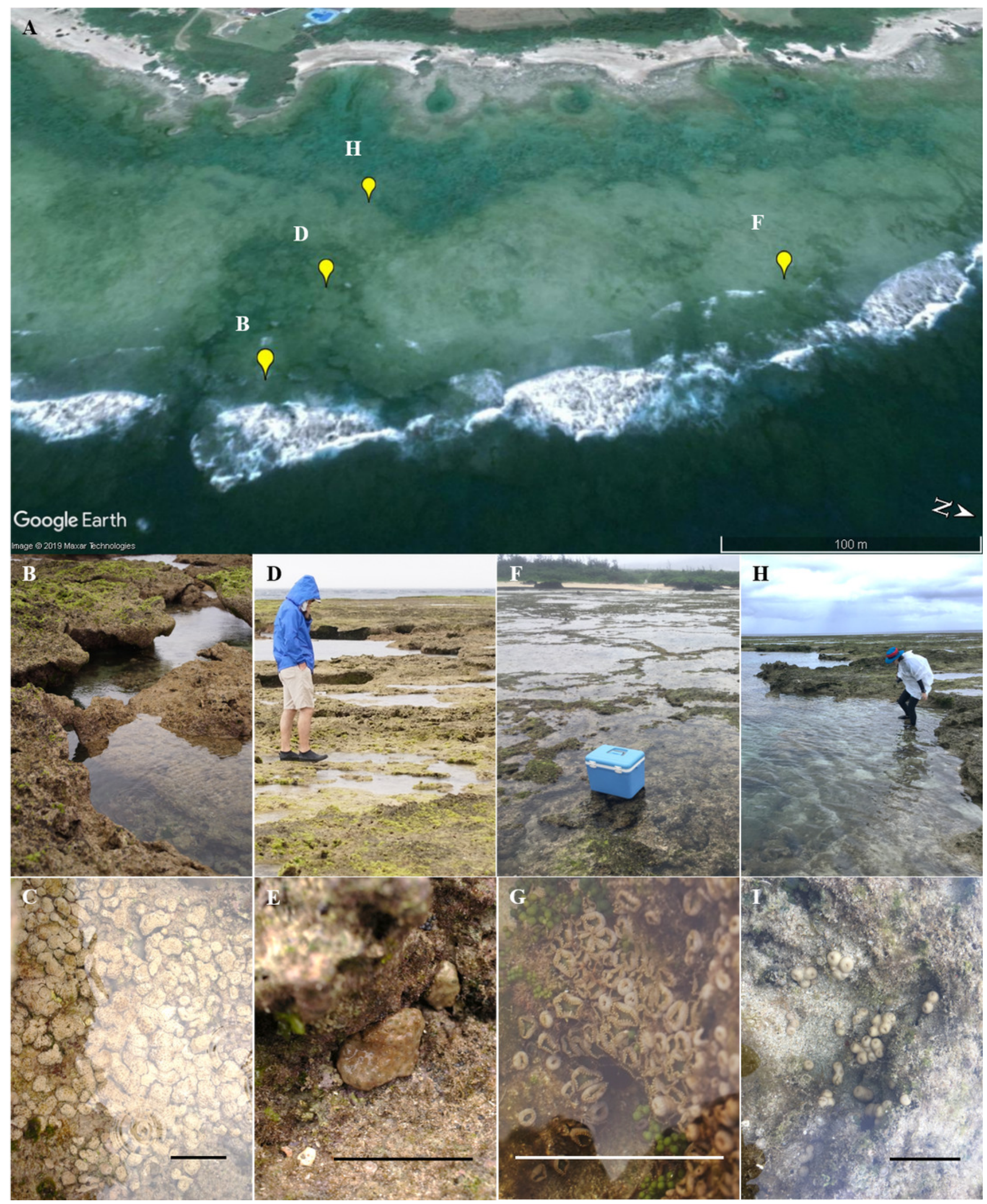




\section{Figure 3}

Haplotype network tree constructed with nuclear ITS-rDNA region alignment using TCS networks method.

Scale represents number of sequences with circle sizes proportional to haplotype frequency. Colors represent Palythoa species: red, P. tuberculosa; yellow, P. sp. yoron; blue, P. mutuki; green, $P$. aff. mutuki.

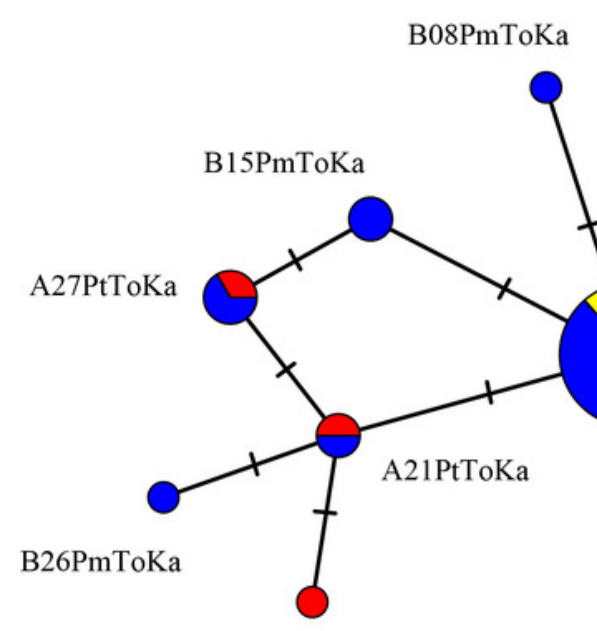

A24PtToKa

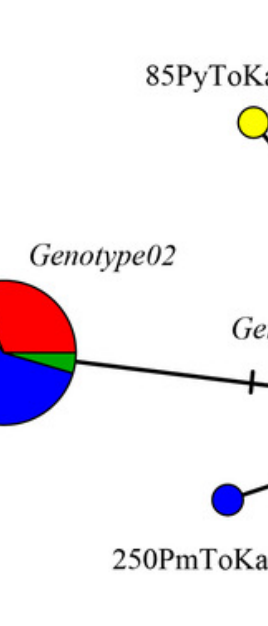

(1)

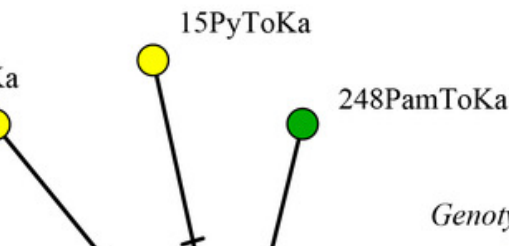

Genotype03

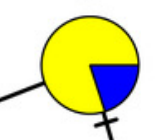
Genotype01

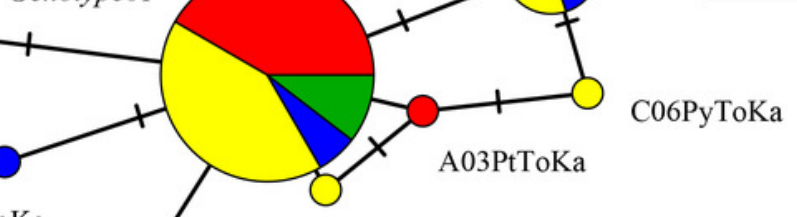

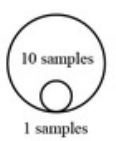

P. tuberculosa

$P$. sp. yoron

P. mutuki

P. aff. mutuki

A12PtToKa 


\section{Figure 4}

Molecular phylogenetic tree of Symbiodiniaceae of Palythoa species using mitochondrial $\operatorname{psbA}^{\text {ncr }}$ forward region.

Bootstrap values of maximum likelihood (ML) and neighbor joining (NJ) methods, and posterior probability (PP) are shown more than $70 \%$ for ML and NJ, and more than 0.95 for PP at the nodes, respectively. Scale bars indicate substitutions per site. Colored letters and colored diagrams represent $P a l y t h o a$ species and their habitats, respectively: red, $P$. tuberculosa; yellow, P. sp. yoron; blue, P. mutuki; green, $P$. aff. mutuki; circle in pink, reef edge; triangle in purple, reef flat; square in orange, backreef moat. 


\section{Legends \\ P. tuberculosa \\ $P$. sp. yoron \\ P. mutuki \\ P. aff. mutuki \\ Reef edge \\ - Reef flat \\ - Backreef moat}

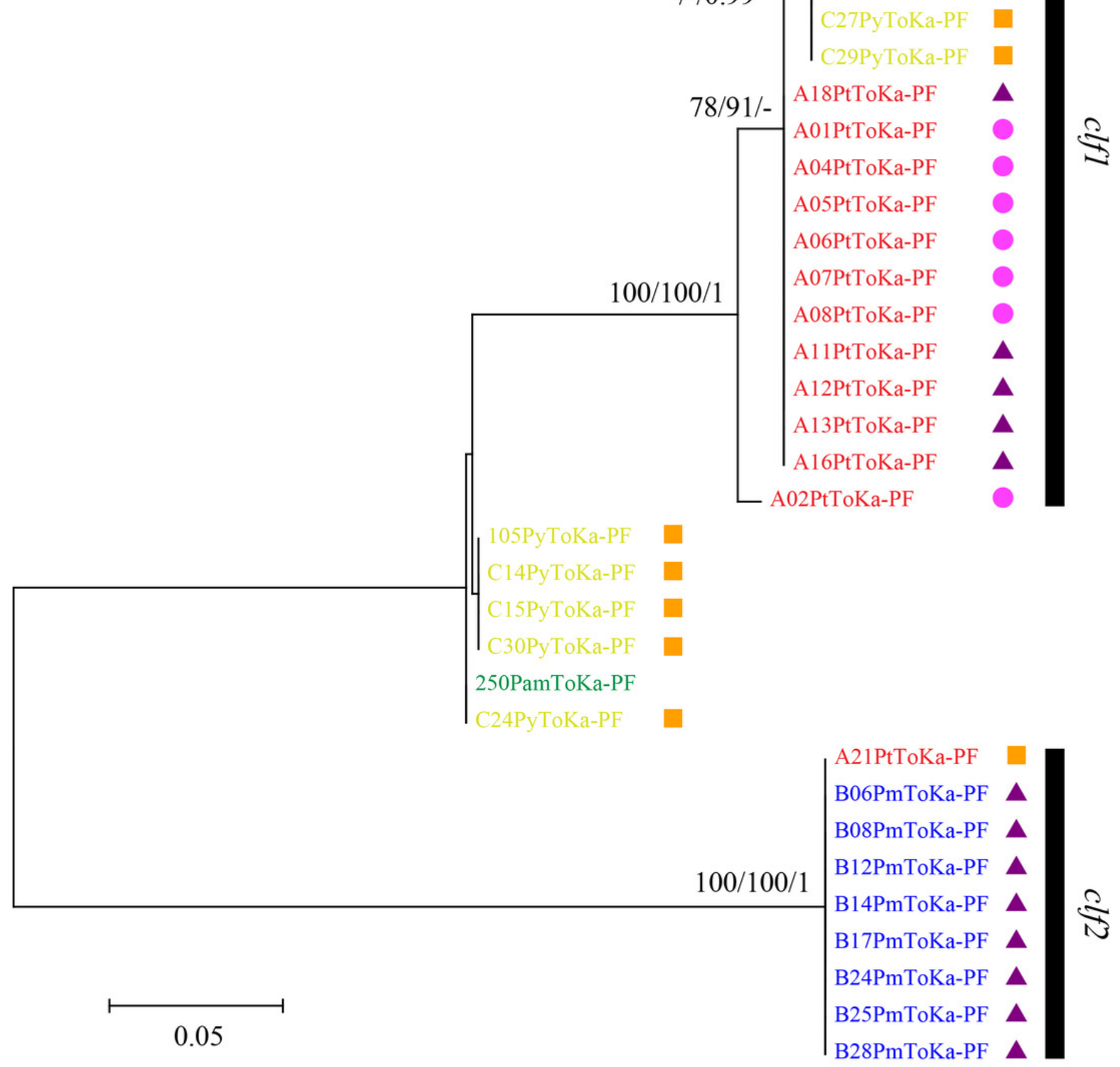




\section{Figure 5}

Molecular phylogenetic tree of Symbiodiniaceae of Palythoa species using mitochondrial $\operatorname{psbA}^{\text {ncr }}$ reverse region.

Bootstrap values of maximum likelihood (ML) and neighbor joining (NJ) methods, and posterior probability (PP) are shown more than $70 \%$ for ML and NJ, and more than 0.95 for PP at the nodes, respectively. Scale bars indicate substitutions per site. Colored letters and colored diagrams represent $P a l y t h o a$ species and their habitats, respectively: red, $P$. tuberculosa; yellow, P. sp. yoron; blue, $P$. mutuki; green, $P$. aff. mutuki; circle in pink, reef edge; triangle in purple, reef flat; square in orange, backreef moat. 


\begin{tabular}{|c|c|}
\hline & P. tuberculosa \\
\hline & P. mutuki \\
\hline & P. aff. mutuki \\
\hline & Reef edge \\
\hline $\boldsymbol{\Delta}$ & Reef flat \\
\hline$\square$ & Backreef moat \\
\hline
\end{tabular}

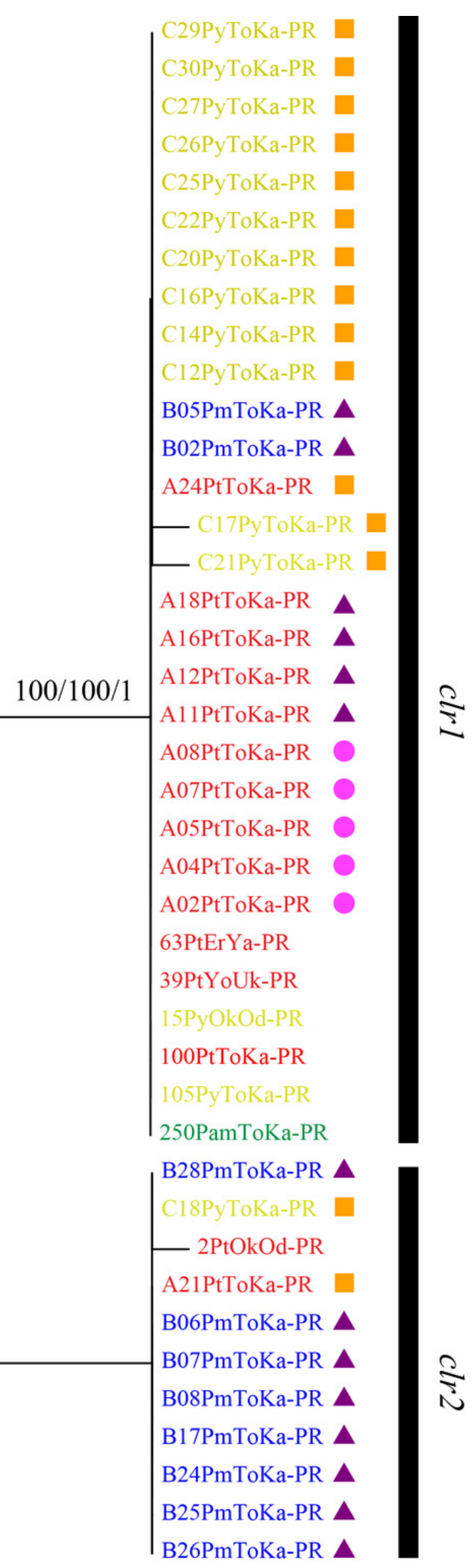

